\title{
Ocular motility findings in chronic progressive external ophthalmoplegia
}

\begin{abstract}
Aims To characterise the ocular motility features of chronic progressive external ophthalmoplegia by quantitative and semiquantitative means.

To assess the prevalence of diplopia and the binocular adaptations to nonaligned visual axes.

Method We studied 25 patients with chronic progressive external ophthalmoplegia. In each case muscle biopsies were consistent with mitochondrial myopathy. All patients underwent cover test in the primary position, assessment of binocular status, and measurement of uniocular fields of fixation using the Goldmann perimeter. Results A total of $23(92 \%)$ patients had an exo-deviation, with six $(26 \%)$ of those having

an associated vertical deviation: 12 patients

were binocular. Of the 13 patients with a manifest deviation seven had diplopia and six had suppression. Of all paired extra-ocular muscles (EOM), $68 \%$ had symmetry of movement within $5^{\circ}$ of each other.

Conclusion Almost all patients had an exodeviation. Diplopia was more common than expected. The majority of patients had symmetry of EOM limitation.

Eye (2005) 19, 258-263. doi:10.1038/sj.eye.6701488

Published online 23 July 2004
\end{abstract}

${ }^{1}$ Department of Ophthalmology Royal Victoria Infirmary Queen Victoria Road Newcastle upon, Tyne

${ }^{2}$ Department of Neurology The University of Newcastle upon, Tyne

\section{Correspondence:}

PG Griffiths

Department of

Ophthalmology

Claremont Wing Royal

Victoria Infirmary

Queen Victoria Road

Newcastle upon

Tyne NE1 4LP, UK

Tel: + 441912825447

Fax: +441912275246

E-mail: p.g.griffiths@

ncl.ac.uk

Received: 6 August 2003 Accepted: 12 November 2003

Published online: 23 July 2004
Keywords: ophthalmoplegia; mitochondrial myopathy

\section{Introduction}

Chronic progressive external ophthalmoplegia (CPEO) is a slowly progressive condition characterised by restriction of eye movements, ptosis, and orbicularis weakness. Extra-ocular muscles (EOM) may be slowly paralysed, either in isolation or in association with other
C Richardson', T Smith', A Schaefer², D Turnbull ${ }^{2}$ and P Griffiths' neurological features. Credit for the first description of CPEO is usually given to von Graefe. ${ }^{1} \mathrm{CPEO}$ is a mitochondrial myopathy associated with deletions, multiple deletions, or point mutations of mitochondrial DNA (mtDNA). ${ }^{2-4}$ Previous descriptions of CPEO predate the existence of molecular genetic testing, and such series may have contained different types of ophthalmoplegia. ${ }^{5}$ Previous studies of patients with biopsy-proven mitochondrial myopathy do not contain a detailed account of the pattern of ophthalmoplegia. ${ }^{6,7}$

We aimed to further characterise the phenotype of CPEO by quantitative means in a population of patients with ophthalmoplegia and skeletal muscle biopsy consistent with mitochondrial myopathy.

\section{Method}

We prospectively recruited 25 patients with known CPEO, attending neuro-ophthalmology clinics. All patients had positive muscle biopsies from vastus lateralis muscle, characterised by a mosaic of cytochrome $c$ oxidase (COX)-deficient fibres and mtDNA deletions, multiple deletions or point mutations, in muscle homogenates.

Testing was standardised using a proforma, devised to record visual acuity and other orthoptic tests. All tests were performed using the patient's corrective glasses. If there was a ptosis obscuring the pupil, the lids were lifted for testing. Cover test and prism cover test were performed for near and distance in the primary position.

Worth's lights were performed at near and distance fixation, in patients with a manifest deviation, to assess suppression or diplopia. Using macular slides, the synoptophore established whether patients had fusion and stereopsis, or suppression, at their corrected angle of deviation. 
Uniocular fields of fixation were used to measure the excursion of individual EOM, as proposed by Haggerty et al. ${ }^{8}$ This technique has been modified from the current method of testing uniocular fields ${ }^{9}$ and uses the Goldmann perimeter to measure movement in the main field of action of each EOM. One eye is occluded and the patient is asked to follow the smallest dimmest light target possible, to ensure foveal fixation, and indicate when it disappears. The orthoptist can also objectively monitor the extent of eye movement using the Goldmann telescope. The test is performed without spectacle correction because the frames may obscure the target. To avoid head movements during testing, the patient's head is held firmly in place by a chin rest and head strap. Six radial lines are drawn on the Goldmann chart for each eye. These correspond to the angle of purest action of each EOM. For the right eye, these lines were drawn at $0^{\circ}$ corresponding to lateral rectus, $180^{\circ}$ medial rectus, $67^{\circ}$ superior rectus, $216^{\circ}$ superior oblique, $293^{\circ}$ inferior rectus, and $141^{\circ}$ inferior oblique. ${ }^{10}$ The axes are mirrored for the opposite eye. The axes were derived from the angle from the vertical axis that gives the purest action for each EOM.

The symmetry of EOM limitation was defined as a difference of $\leq 5^{\circ}$ between one muscle and its equivalent on the opposite eye, for example, comparing the right medial rectus with the left medial rectus rather than comparing yoke muscles. The muscle scores from the uniocular fields of fixation, for the right eye only, were also used to identify the EOMs that were most or least affected. Muscle scores from the CPEO patients were compared with normal population values for the right eye only. We did not control for age and sex.

\section{Results}

In all, 25 patients had an orthoptic assessment. There were 13 male and 12 female patients, with a median age of 46 years (ranging from 30 to 70 years). The age, sex, and proportion of COX deficient fibres in the vastus lateralis muscle of our patients are summarised in Table 1.

Five patients were unable to perform uniocular fields of fixation either from an inability to take up central fixation because of severe muscle limitation or a central field defect. The 35 normal patients consisted of 15 male and 20 female patients, with a median age of 38 years (ranging from 21 to 59 years).

Table 1 Characteristics of patients with chronic progressive external ophthalmoplegia showing age, sex, ophthalmoplegia score, percentage cytochrome $c$ oxidase (COX)-deficient fibres, and type of mitochondrial DNA mutation

\begin{tabular}{|c|c|c|c|c|c|}
\hline Patient no. & Age & $\operatorname{Sex}$ & Ophthalmoplegia score & $\%$ COX-deficient fibres & mtDNA mutation \\
\hline 1 & 30 & $\mathrm{~F}$ & 62 & Positive $^{\mathrm{a}}$ & Single deletion \\
\hline 2 & 30 & $\mathrm{M}$ & 94 & 10 & Single deletion \\
\hline 3 & 31 & M & $<30$ & 50 & Single deletion \\
\hline 4 & 33 & $\mathrm{M}$ & $<30$ & Positive $^{\mathrm{a}}$ & Single deletion \\
\hline 5 & 34 & $\mathrm{M}$ & 149 & 20 & Multiple deletions \\
\hline 6 & 34 & $\mathrm{~F}$ & 189 & Positive $^{\mathrm{a}}$ & Single deletion \\
\hline 7 & 36 & $\mathrm{M}$ & 205 & 5 & Single deletion \\
\hline 8 & 37 & $\mathrm{M}$ & 120 & 25 & Single deletion \\
\hline 9 & 38 & $\mathrm{~F}$ & 82 & 40 & Single deletion \\
\hline 10 & 38 & $\mathrm{~F}$ & 90 & 10 & Single deletion \\
\hline 11 & 42 & $\mathrm{~F}$ & 147 & 20 & Multiple deletions \\
\hline 12 & 46 & $\mathrm{~F}$ & 230 & 30 & Single deletion \\
\hline 13 & 46 & $\mathrm{M}$ & 101 & 5 & Multiple deletions \\
\hline 14 & 47 & $\mathrm{~F}$ & 193 & 1 & Multiple deletions \\
\hline 15 & 49 & $\mathrm{M}$ & 187 & 15 & Multiple deletions \\
\hline 16 & 52 & $\mathrm{~F}$ & 114 & 10 & Multiple deletions \\
\hline 17 & 53 & $\mathrm{M}$ & 118 & 5 & Single deletions \\
\hline 18 & 54 & $\mathrm{M}$ & 82 & 50 & Single deletion \\
\hline 19 & 56 & $\mathrm{~F}$ & 270 & 1 & Multiple deletions \\
\hline 20 & 58 & M & 97 & 10 & Single deletion \\
\hline 21 & 61 & $\mathrm{~F}$ & 170 & 1 & Multiple deletions \\
\hline 22 & 64 & $\mathrm{~F}$ & 116 & 10 & Single deletion \\
\hline 23 & 68 & $\mathrm{~F}$ & $<30$ & Positive $^{\mathrm{a}}$ & Single deletion \\
\hline 24 & 69 & $\mathrm{M}$ & 132 & 2 & Multiple deletions \\
\hline 25 & 70 & $\mathrm{M}$ & 124 & 20 & Point mutation \\
\hline
\end{tabular}

Positive $^{\mathrm{a}}$ means that the biopsy was done elsewhere and accurate quantitation of the percentage of COX-deficient fibres was not obtained or that the biopsy was done in Newcastle prior to our current protocol for quantitating COX-deficient fibres. 


\section{Type of deviation}

There were $23(92 \%)$ patients with an exo-deviation and six $(26 \%)$ of these patients had an associated vertical deviation. The remaining two patients had either no apparent deviation or a vertical deviation only. Patients with exo-deviations had a mean angle of 20 prism dioptres (PD) at $1 / 3 \mathrm{rd} \mathrm{m}$ (ranging from 2 to $90 \mathrm{PD}$ ), and of $11 \mathrm{PD}$ at $6 \mathrm{~m}$ (ranging from 1 to $90 \mathrm{PD}$ ). The mean vertical angle was $4 \mathrm{PD}$ at $1 / 3 \mathrm{rd} \mathrm{m}$ (ranging from 1 to $12 \mathrm{PD}$ ) and $5 \mathrm{PD}$ at $6 \mathrm{~m}$ (ranging from 1 to $12 \mathrm{PD}$ ).

\section{Prevalence of diplopia/suppression}

Of the 25 patients with CPEO, 12 were binocular and 13 had a manifest deviation. Of those that had a manifest deviation, seven patients had diplopia and six patients had suppression.

Of the six patients with suppression, three had constant suppression with Worth's lights and with the synoptophore. The other three patients had intermittent suppression for either near or distance.

\section{Symmetry of ophthalmoplegia in CPEO}

Our results, summarised in Table 2, show a striking degree of symmetry when comparing equivalent muscles of each eye, that is, comparing the right medial rectus with the left medial rectus rather than comparing yoke muscles. When the results for all muscles pairs were combined, $68 \%$ of all paired EOMs showed symmetry of movement between $0^{\circ}$ and $5^{\circ}$. The range for individual muscle pairings was between $55 \%$ for the superior oblique muscles and $75 \%$ for the superior rectus and inferior rectus muscles.

\section{Extent and pattern of EOM limitation}

The mean score of movement for individual EOMs of the right eye, of 20 CPEO patients, was calculated with $95 \%$ confidence interval, as shown in Figure 1 and Table 3. This was compared to a normal population of 35 patients.

The percentage of limitation from normal muscle excursion scores was also calculated in patients with CPEO. The limitation of movement from normal values ranged from $41 \%$ for the superior oblique to $61 \%$ for the superior rectus (Table 3). The percentage limitation from normal values suggests that the superior oblique is the least affected EOM in patients with CPEO. This is illustrated in Figure 1, which shows the mean movement of each EOM for the normal population and our patients with CPEO.

Table 2 Symmetry of ophthalmoplegia

\begin{tabular}{lcccccc}
\hline Difference (deg) & Medial rectus & Lateral rectus & Superior rectus & Inferior oblique & Inferior rectus & Superior oblique \\
\hline $0-5$ & $14(70)$ & $12(60)$ & $18(90)$ & $12(60)$ & $14(70)$ & $11(55)$ \\
$6-11$ & 5 & 4 & 1 & 4 & 5 & 7 \\
$12-17$ & 1 & 3 & 1 & 3 & 0 & 2 \\
$>18$ & 0 & 1 & 0 & 1 & 0 \\
\hline
\end{tabular}

Figures indicate the number of patients with ophthalmoplegia scores within $5^{\circ}, 6-11^{\circ}, 12-17^{\circ}$, and $>18^{\circ}$ comparing equivalent muscles of each eye. That is, comparing the right medial rectus with the left medial rectus, etc. The total number of patients is 21 because four patients had fields of movement that were too small to plot accurately or their fixation was too poor. Figures in brackets are the $\%$ of patients with ophthalmoplegia scores within $5^{\circ}$ for each muscle.

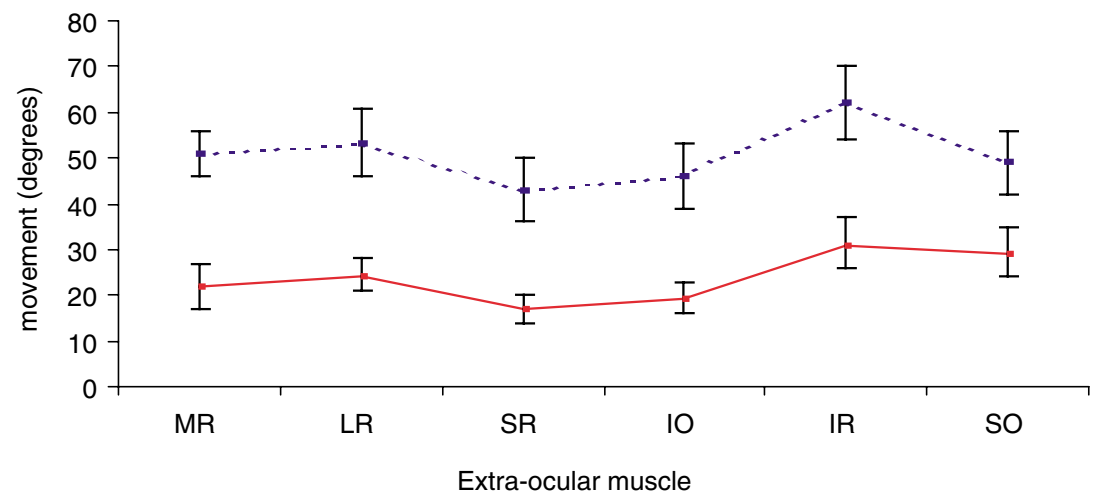

Figure 1 Mean excursion in the field of action of each EOM for 21 patients with CPEO (solid line) and 35 normal patients (dotted line). Vertical bars represent $95 \%$ confidence intervals. 
Table 3 Average excursion in degrees, in the field of action of each EOM, for 21 right eyes from patients with chronic progressive external ophthalmoplegia and 35 right eyes of normal patients

\begin{tabular}{lcccccc}
\hline & \multicolumn{5}{c}{ Extra-ocular muscles (right eye) } \\
\cline { 2 - 7 } & Medial rectus & Lateral rectus & Superior rectus & Inferior oblique & Inferior rectus & Superior oblique \\
\hline CPEO & $22(17-27)$ & $24(20-27)$ & $17(14-20)$ & $19(15-22)$ & $31(25-36)$ & $29(23-34)$ \\
Normal & $51(46-56)$ & $53(45-60)$ & $43(36-50)$ & $46(39-53)$ & $62(54-70)$ & $49(42-56)$ \\
CPEO \% limitation & 57 & 54 & 61 & 59 & 50 & 41 \\
\hline
\end{tabular}

Figures in brackets are 95\% confidence intervals.

It appears from Figure 1 that the inferior rectus is least affected in CPEO patients, showing the greatest excursion of muscle movement on the graph. However, when proportionately compared to the normal value, the superior oblique is the least affected EOM.

\section{Discussion}

Ophthalmoplegia is the commonest manifestation of mitochondrial cytopathy. In one series of 66 patients with mitochondrial cytopathy, 48 developed ptosis or weakness of EOMs and in 32 of these cases the ophthalmoplegia was severe, with less than $10 \%$ of the normal range of eye movement. ${ }^{6}$ There are significant differences between EOM and skeletal muscle, but it is not known why EOM are preferentially affected by mitochondrial disorders. EOM have smaller motor unit sizes, higher motor neurone discharge rates, ${ }^{11}$ higher blood flow, ${ }^{12,13}$ and higher mitochondrial volume fractions ${ }^{14}$ compared to skeletal muscle. This suggests that the energy requirements and therefore susceptibility to mitochondrial dysfunction may be higher.

Although CPEO is a descriptive term, we take it as being synonymous with a mitochondrial cytopathy causing progressive restriction of eye movements. For this reason, our diagnostic standard was the finding of COX-deficient fibres and deleted or mutated mtDNA in muscle biopsies from the vastus lateralis muscle. ${ }^{7,15}$ These criteria may have excluded cases where the causative mtDNA deletion segregated to EMOs and was present at undetectable levels in the vastus lateralis muscle. However, excluding these patients ensures that we have a homogeneous group of patients with ophthalmoplegia due to mitochondrial dysfunction. We believe that this is the largest series of patients with molecular genetic characterisation to have their eye movements recorded. Other studies have been largely descriptive in documenting eye movements whereas our study uses quantitative and semiquantitative methods.

One possible source of error in recording eye movements from patients with $\mathrm{CPEO}$ is that the target may be followed by making head movements rather than eye movements, so that we overestimate the range of movement. During the test, we limited movement with the aid of a head strap and a chin rest. Any head movements that did occur could be detected by observation through the observation telescope. One possible improvement to our technique would be the incorporation of a 'bite bar' to further stabilise the head position.

Although we have data for the test/retest variability in normal patients, which measures $\pm 4^{\circ}, 8$ because of the large distances many of our patients with $\mathrm{CPEO}$ have to travel we have not been able to test them on separate occasions.

We caution against drawing conclusions about individual muscles as limitations in one direction of gaze may relate to failure of relaxation of the ipsilateral antagonist as much as underaction of a single muscle. Our reason for choosing the above technique is to use a standardised method, using logically chosen axes, that could be replicated by other workers. The relative sparing of the superior oblique may, at least in part, be artefactual. In normal individuals looking downwards and nasally, the target may be obscured by the nose, underestimating the normal excursion in the direction of action of the superior oblique muscle. This underestimation would not occur in those patients with ophthalmoplegia, resulting in apparent sparing of the superior oblique muscle.

When comparing the same muscle of each eye, for example right medial rectus and left medial rectus, the degree of symmetry is striking. Eye movements in the direction of action of each muscle were within $5^{\circ}$ in $68 \%$ of cases.

The symmetry of ophthalmoplegia may be the result of equal accumulation of deletions or mutations in all EOMs, or could reflect a significant central or supranuclear component to the ophthalmoplegia of CPEO. There is evidence of brainstem abnormalities in $\mathrm{CPEO}$, from both autopsy studies ${ }^{16}$ and nuclear magnetic resonance spectroscopy, which shows widespread alteration of metabolic profile in the brain. ${ }^{17}$ There is also 
clinical evidence of more widespread brainstem dysfunction in CPEO. An increased latency of the blink response has been measured ${ }_{1}^{18}$ and in one case an increased range of eye movement was observed to oculocephalic testing compared to voluntary eye movements; ${ }^{19}$ a hallmark of a supranuclear eye movement problem.

There did not appear to be any correlation between non-ocular features such as pigmentary retinopathy and ophthalmoplegia score. However, most of our patients only had ophthalmolpegia, so we hesitate to draw any firm conclusions on this matter without a greater numbers of patients.

Our results show that the fields of uniocular fixation are concentrically contracted with modest relative sparing of downgaze observed elsewhere. ${ }^{20}$

In all, $48 \%$ of our patients had bifoveal fixation. If a deviation was present, it was almost invariably an exodeviation with or without an additional vertical deviation. If an eso-deviation is present, the diagnosis of CPEO should be reviewed. In one case referred with CPEO, but not included in this series, a small esodeviation was present. A subsequent muscle biopsy did not confirm a mitochondrial myopathy, and eye movement recordings were more consistent with a supranuclear ophthalmoplegia.

While it is true that most patients with CPEO do not experience diplopia, our results show that a significant minority (28\%) do. Of those with a manifest deviation, $54 \%$ were troubled by diplopia, the other $46 \%$ developed suppression. It is surprising that suppression should develop so late in life, as the sensitive period during which abnormal visual experience affects visual development is thought to finish at about 7 years of age. ${ }^{21-23} \mathrm{~A}$ suppression response was unequivocally demonstrated on either the Worth 4 dot test and using the synoptophore, so it seems unlikely that our patients were ignoring the second image.

Other chronic conditions that affect binocular function in adult life can result in suppression or loss of normal binocular function. For example, patients with asymmetric keratoconus may develop suppression, ${ }^{24}$ and long-standing dense cataract in adults can permanently disrupt binocular function. ${ }^{25-27}$ The adult visual system may be more plastic than previously recognised, and the finding of suppression does not prove that an ocular deviation dates from childhood. We did not demonstrate anomalous retinal correspondence in any of our cases, although one author has suggested that this may occur in CPEO. $^{28}$

The ophthalmoplegia of CPEO is said to be symmetrical, slowly progressive with relative sparing of downgaze, and is only rarely associated with diplopia.
Our results broadly support this view, but diplopia may be more common than previously thought.

We have shown that it is possible to quantitate ophthalmoplegia so that we have a reliable end point for possible future trials of treatments for mitochondrial myopathies.

\section{References}

1 von Graefe A. Verhadlungen arztlicher Gesselschaften. Berlin Klin Wochenschr 1868; 5: 125.

2 Holt IJ, Harding AE, Morgan-Hughes JA. Deletions in mitochondrial DNA in patients with mitochondrial myopathies. Nature 1988; 331: 717-719.

3 Zeviani M, Moraes CT, Di Mauro S, Nakase H, Bonilla E, Schon EA et al. Deletions of mitochondrial DNA in KearnsSayre syndrome. Neurology 1988; 38: 1339-1346.

4 Moraes CT, Di Mauro S, Zeviani M, Lombes A, Shanske S, Miranda A et al. Mitochondrial DNA deletions in chronic progressive external ophthalmoplegia and Kearns Sayre syndrome. N Eng J Med 1989; 320: 1293-1299.

5 Stanworth A. Ocular Myopathies. Trans Ophthalmol Soc UK 1963; 83: 515-530.

6 Petty RK, Harding AE, Morgan Hughes JA. The clinical features of mitochondrial myopathy. Brain 1986; 109: 915-938.

7 Jackson MJ, Schaefer JA, Johnson MA, Morris AA, Turnbull DM, Bindoff LA. Presentation and clinical investigation of mitochondrial respiratory chain disease. Brain 1995; 118: 339-357.

8 Haggerty H, Richardson S, Mitchel K, Dickinson A. A modified method for the reliable assessment of uniocular fields of fixation. In: Trans European Strabismological Association. 27th Annual Meeting. Florence, 2001.

9 von Noorden GK. Binocular Vision and Motility: Theory and Management of Strabismus, 5th ed Mosby: St Louis, 1996.

10 Snell R, Lemp M. Clinical Anatomy of The Eye. Blackwell Scientific Publications: Oxford, 1989.

11 Robinson DA. Oculomotor unit behaviour in the monkey. J Neurophysiol 1970; 33: 393-404.

12 Spencer RF, Porter JD (eds). Structural Organisation of The Extraocular Muscles. Elsevier: New York, 1988.

13 Wooton GF, Reis DJ. Blood flow in extraocular muscle of cat. Arch Neurol 1972; 26: 350-352.

14 Borchert MS. Diseases of the ocular muscles. In: Albert DM, Jakobiec FA (eds). Principles and Practice of Ophthalmology: Clinical Practice, 1st ed. W B Saunders: Philadelphia, 1994.

15 McFarland R, Taylor R, Turnbull D. The neurology of mitochondrial DNA disease. Lancet 2002; 1: 343-351.

16 Daroff RB, Solitare GB, Pincus JH, Glaser GH. Spongiform encephalopathy with chronic progressive external ophthalmoplegia: central ophthalmoplegia mimicking ocular myopathy. Neurology 1966; 16: 161-169.

17 Salvan A, Vion-Dury J, Confrot-Gouny S, Sangla I, Pouget J, Cozzone P. Brain metaboloic profiles obtained by proton MRS in two forms mitochondriopathies: Leber's hereditary optic neuropathy and chronic progressive external ophthalmoplegia. Eur Neurol 1998; 40(1): 46-49.

18 Koutromanidis M, Papadimitriou A, Bouzas A, Avramidis T, Papathanassopoulos P, Howard RS et al. Reduced brain stem excitability in mitochondrial myopathy: evidence for 
early detection with blink reflex habituation studies. Muscle Nerve 1996; 19: 1586-1595.

19 Gupta SR, Brignell M, Gujrati M, Lee JM. Supranuclear eye movement dysfunction in mitochondrial myopathy with tRNA $^{\text {LEU }}$ mutation. J Neuro-Ophthalmol 1995; 15: 20-25.

20 Miller NR. Walsh and Hoyt's Clinical Neuro-ophthalmology, 4th ed. William \& Wilkins: Baltimore, 1985.

21 Boothe R, Dobson V, Teller D. Postnatal development of vision in human and non human primates. Ann Rev Neurosci 1985; 8: 485-545.

22 von Noorden G. Amblyopia: a multidisciplinary approach. Invest Ophthalmol Vis Sci 1985; 26: 1704-1716.

23 Vaegan, Taylor D. Critical period for deprivation amblyopia. Trans Ophthal Soc UK 1979; 99: 432-439.

24 Sherafat H, White JS, Pullam K, Adams G, Sloper J. Anomalies of binocular function in patients with longstanding keratoconus. Br J Ophthalmol 2001; 85: 1057-1060.

25 Hamed L, Helveston E, Ellis F. Persistent binocular diplopia after cataract surgery. Am J Ophthalmol 1977; 103: 741-744.

26 Pratt-Johnson J, Tillson G. Intractable diplopia after vision restoration in unilateral cataract. Am J Ophthalmol 1989; 107: 23-26.

27 Sharkey J, Sellars P. Acquired central fusion disruption following cataract extraction.J Paediatr Ophthalmol Strabismus 1994; 31: 391-393.

28 Bastiaensen L, Notermans S, Ramaekers C, van Dijke B, Joosten E, Jaspar $\mathrm{H}$ et al. Kearns syndrome or Kearns disease. Further evidence of a genuine entity in a case with uncommon features. Ophthalmologica 1982; 184: $40-50$. 